\title{
CYANIDE DETERMINATION WITH A MODIFIED NINHYDRIN REAGENT USING N-ACETYL CYSTEINE IN THE PRESENCE OF HEAVY METAL IONS
}

\author{
IOAN-MARIUS MIHAESCU ${ }^{*}$, \\ "Chemistry Department, Al. I. Cuza University of Iasi, 11 Carol I, Iasi-700506, Romania
}

(Received: December 1, 2010 - Accepted: October 13, 2010)

\begin{abstract}
Sensitive and selective, but fast and simple assays of cyanide ion in waste and natural waters, as well as in biological samples are required in case of accidental pollution with such species. Cyanide reaction with ninhydrin has been recommended for instant detection of small traces of cyanide $\left(\right.$ detection limit $\left.1.5 \mathrm{ng} \mathrm{ml}^{-1}\right)$. However, the oxidizers and heavy metal ions, such as $\mathrm{Hg}, \mathrm{Cu}, \mathrm{Ag}$ may interfere with the determinations. Therefore, we report here cyanide determination with ninhydrin and its usage in monitoring polluted water with heavy metals. The effect of heavy metals and SH-compounds were studied in order to increase the method range of use. $\mathrm{N}$-acetyl cysteine proved to be a selective reagent for protection of cyanide detection and determination against the interference of heavy metal ions.
\end{abstract}

Keywords: Ninhydrin, cyanide determination, n-acetyl cysteine, heavy metal ions.

\section{INTRODUCTION}

Cyanide is highly toxic to human beings; however it may be present in water as a result of industrial contamination. Despite its toxicity, cyanide in solution was used to dissolve heavy metals out of exposed piles of waste rock, a leaching process that allows extraction of precious metals such as gold and silver. Mining activities affect health via water through the method of extraction, contamination of local water sources, as well as having harmful effects on the environment such as beach erosion from sand mining or by longer term effects on reducing biodiversity or fish populations. ${ }^{1}$ The concentration ranges of cyanide in waste effluents $(0.70-52.0 \mathrm{mg} / \mathrm{L})$ may be well above its acute toxicity levels. ${ }^{2}$ Metal-containing wastewaters, arising from gold extraction, electroplating, metal finishing, metal hardening and printed circuit board manufacturing, contain up to $300 \mathrm{mg}$ cyanide $\mathrm{mg} \mathrm{L}^{-1} .^{3}$ In the wastewaters, cyanide complexes with heavy metals (i.g. copper, nickel, zinc, cadmium, iron, silver, gold etc) with varying stabilities and toxicities. ${ }^{4}$

Cyanide can be determined using colorimetric, potentiometric, amperometric, fluorimetric and chromatographic methods. More than sixty spectrophotometric methods like Aldridge's method are still in use. ${ }^{5}$ The turbiditometric reaction between silver nitrate and cyanide can be monitored potentiometrically using silver, gold and platinum electrodes. ${ }^{6}$ PPO/ clay biosensors have the lowest detection limit $(0.1 \mathrm{nM})$ for cyanide. ${ }^{7}$

In environmental wastes, free cyanide can be determined after using time consuming techniques like solvent extraction, gas dialysis, microdiffusion, pervaporation. ${ }^{8}$ Without using these techniques, any of above mentioned methods aren't usable in the presence of heavy metals.

Ninhydrin in the presence of sodium carbonate was found to be a highly sensitive and selective chemosensor for cyanide in pure aqueous solutions, with a detection limit of as little as $0.025 \mu \mathrm{g} \mathrm{ml}^{-1} \mathrm{CN}^{-}$and a color change that could be observed by the naked eye. ${ }^{9,10,11}$ Santelli et al. ${ }^{12}$ improved much the assay for detection of small traces of cyanide. Detection limit $\left(1.5 \mathrm{ng} \mathrm{mL}^{-1}\right)$ has become comparable with that of the fluorimetric methods. ${ }^{13,14}$ This method has attracted much attention and has been constantly improved so far. ${ }^{12,15}$

Despite its performance, the oxidizers and heavy metal ions, such as $\mathrm{Hg}$, $\mathrm{Cu}, \mathrm{Ag}$ may interfere with cyanide determination or even detection.

Therefore, this paper aims at presenting a few improvements which enable ninhydrin reagent to be used in detection and determination in the presence of heavy metal ions. The interference by these metals was investigated and a modification of the ninhydrin reagent is discussed.

\section{EXPERIMENTAL}

Reagents

All chemicals were of analytical reagent grade, and all solutions were prepared with milliQ grade water with $\mathrm{R}=18.2 \Omega$. A standard solution of cyanide was prepared according to Nagaraja et al. ${ }^{9}$ A $0.225 \%$ aqueous solution of ninhydrin in $2 \%$ sodium carbonate was prepared. Nitrogen was bubbled into the most solutions to release the interfering oxygen. Mercury chloride, copper sulfate, cadmium chloride, silver nitrate, manganese chloride and zinc chloride were purchased from Merck. Several solutions of these metals were made and introduced both in the ninhydrin reagent and cyanide solutions up to the desired concentrations.

Instrument

A Libbra S35 PC UV/VIS spectrophotometer with 1-cm matched cells of quartz was used for spectral measurements. The $\mathrm{pH}$ values were measured with a HANNA PH 211 microprocessor $\mathrm{pH}$ meter. The heating was performed with an AREX heating magnetic stirrer. A Mikro $22 \mathrm{R}$ centrifuge was used as well.

\section{Procedure}

Samples of $1 \mathrm{~mL}$ of cyanide solution containing maximum $2 \mu \mathrm{g} \mathrm{mL}^{-1}$ were pipetted into the spectrophotometer cuvette and $0.5 \mathrm{~mL}$ of ninhydrin reagent was added. To increase the sensitivity of the reaction or to check the reagent stability, potassium hydroxide solution was added. The resulting solution was bubbled with nitrogen, capped and let to develop color. In the most cases, nitrogen was not used in order measure as quick as possible the absorbance. However, each solution used in the reaction was previously purged with nitrogen. The deep-red or deep-blue color was measured at $485 \mathrm{~nm}$ and 590 $\mathrm{nm}$, respectively. A reagent blank with no cyanide was used.

The UV-Vis spectra were recorded in the range from $200 \mathrm{~nm}$ to $700 \mathrm{~nm}$, as well.

N-Acetyl cysteine, glutathione, cysteine, and serine were introduced to evaluate the interference of heavy metals.

Effect of various concentrations of metal ions was followed at the $2 \mu \mathrm{g}$ $\mathrm{mL}^{-1} \mathrm{KCN}$ and $0.225 \%$ ninhydrin in $2 \%$ sodium carbonate.

\section{RESULTS}

\section{Interference studies}

The interfering effects of heavy metal ions, which may co-exist with cyanide in gold mining and industrial effluents, were investigated. Besides, the effect of some SH-compounds as detoxifying agents and the role of oxygen and other oxidizers were studied.

It is well known that copper ions form a water-soluble 1:2 molar complex with ninhydrin. ${ }^{12}$ However, silver, mercury, nickel, copper and other ions may form metal-cyanide coordination compounds, which hinder the reaction between cyanide and ninhydrin. Nevertheless, silver and mercuric ions interfere with cyanide determination, making precipitates with ninhydrin reagent under alkaline conditions. Our present results confirmed that the formation of complexes between metal ions and cyanide might be the most important event involved in the interference of these ions. Each metal studied had a characteristic interval of concentrations to interfere with the color reaction. 


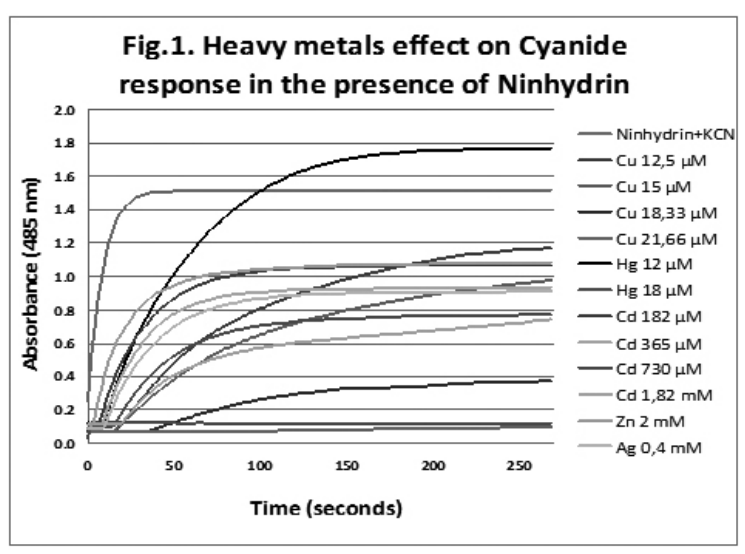

A $2 \mathrm{mM}$ zinc chloride had a low effect on the absorbance of the solution containing cyanide and ninhydrin in the presence of sodium carbonate (Fig. 1). Contrary, silver had different but intense effect on the absorbance, although its concentration was as low as $0.4 \mathrm{mM}$ (Fig. 1). At the same time, these ions proved to change the rate of reaction between cyanide and ninhydrin; silver ions might form cyanide complexes which both hindered the reaction and postponed it.

The effect of mercuric ions (Fig. 1) on the absorbance of ninhydrin-cyanide complex was analyzed using two different concentrations $(12 \mu \mathrm{M}$ and $18 \mu \mathrm{M}$, respectively). The high absorbance at lower concentration was explained by the multiple reactions of mercury ions with cyanide, carbonate, and ninhydrin, which leads to solution opalescence. In the case of high concentration of mercury ions the reaction of ninhydrin with cyanide was completely inhibited

Copper ions (Fig. 1) reduced drastically the absorbance of the red-colored solution in the concentration range from $12.5 \mathrm{mM}$ to $21.66 \mathrm{mM}$. At the same time, the reaction rate decreased much with increasing copper concentration. Higher concentrations of copper also postponed the beginning of color reaction, most probably due to the formation of copper-cyanide complexes.

A similar reaction pattern was observed in the case of cadmium, although the concentrations of cadmium were huge as compared to those of copper (Fig. $1,2)$.

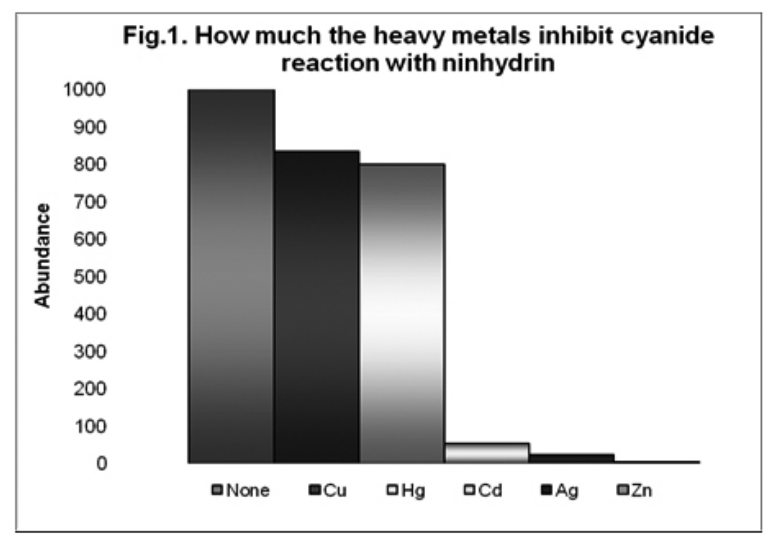

Other metals such as alkaline ones or manganese had no effect on the reaction between cyanide and ninhydrin under alkaline conditions.

The role of SH compounds

$\mathrm{N}$-Acetyl cysteine (NAC) did not interfere with the determinations at concentrations proportional with those of the heavy metals investigated. Only as high as 10-20 times molar concentrations more than those of the metal ions, these SH-compounds interfere by increasing the red color intensity. Therefore, in the case of heavy metal presence as usual in gold mining industry, the use of SH compounds are strongly recommended. These compounds partially avoided heavy metals interference with cyanide determination. We realized samples with the same heavy metals composition as in a case of massive cyanide pollution in Baia Mare, Romania, 2000. The results are shown in table 1. A final concentration of $200 \mu \mathrm{M}$ NAC was used. The results showed that the best way is to introduce NAC in the sample containing metals and cyanide.

All the results were compared with simultaneous analysis with a $\mathrm{CN}^{-}$ selective electrode.

Table 1

\begin{tabular}{|l|c|}
\hline \multicolumn{1}{|c|}{ Sample } & Absorbance \\
Ninhydrin + Metals + Cyanide & 0,085 (blank) \\
Ninhydrin + (Metals+cyanide+NAC) & 1,014 \\
(Ninhydrin + NAC + Metals) + cyanide & 0,562 \\
(Ninhydrin + NAC) + (Metals + cyanide) & 0,216 \\
(Ninhydrin + Metals) + (NAC + cyanide) & 0,985 \\
Ninhydrin + cyanide & 1,48 \\
\hline
\end{tabular}

\section{CONCLUSIONS}

The reaction between cyanide and ninhydrin under alkaline conditions could be useful to identify and determine cyanide in the contaminated environments (water, air, industrial effluents, etc.). The (heavy) metal ions, oxidizers as well as UV light may interfere with the determinations; therefore, many of these interferences are here investigated. Heavy metals such as copper and mercury almost completely inhibit cyanide reaction with ninhydrin, whereas zinc, silver and cadmium are less aggressive. Glutathione and N-acetylcysteine proved to bind heavy metal ions and to eliminate their influence on the reaction. We strongly recommend the usage of NAC or to identify/determine cyanide.

Reagents are easily available, the reaction is very fast and no special devices are necessary.

\section{ACKNOWLEDGEMENTS}

The author gratefully acknowledges Dr. Dirtu A.C. and Prof. Dr. G. Drochioiu for encouragement and theoretical support.

\section{REFERENCES}

1. X. Zhang., C. L. Cheng, X. Wang, B. Zhang, Sensors and Actuators B: Chemical, 129, 152, (2008).

2. C. M. Zvinowanda, J. O. Okonkwo, R. C. Gurira, J. Hazard. Mat., 158, 196, (2008).

3. A. Akcil, T. Mudder, Biotechnol. Lett., 25, 445, (2003).

4. Z. X. Quan, J. W. Bae, S. K. Rhee, Y. G. Cho, S. T. Lee, Biotechnol. Lett., $26,1007,(2004)$.

5. W. N. Aldridge, Analyst, 69, 262, (1944).

6. K. Toth, E. Pungor, Anal. Chim. Acta, 51, 221, (1970).

7. D. Shan, C. Mousty, S. Cosnier, Anal. Chem., 76(1), 178, (2004).

8. H. Sulistyarti, T. J. Cardwell, L. Castro, S. D. Kolev, Anal. Chim. Acta, 390, 133, (1999).

9. P. Nagaraja, M. S. H. Kumar, H. S. Yathirajan, J. S. Prakash, Anal. Sci., 18, 1027, (2002).

10. G. Drochioiu, Talanta, 56, 1163, (2002).

11. G. Drochioiu, Anal. Bioanal. Chem., 372, 744, (2002).

12. R. E. Santelli, A. S. Micelli, M. F. Batista de Carvalho, Spectrosc. Lett., $39,605,(2006)$.

13. A. Sano, M. Takezawa, S. Takitani, Anal. Sci., 2, 491, (1986).

14. K. Gamoh, H.Sawamoto, Anal. Sci., 4, 665, (1988).

15. D. G. Themelis, S. C. Karastogianni, P. D. Tzanavaras, Anal. Chim. Acta, 632, 93, (2009).

16. G. Drochioiu, I. Mangalagiu, E. Avram, K. Popa, A. C. Dirtu, I. Druta, Anal. Sci., 20, 1443, (2004). 